\title{
Peri-implantitis. Part 1: Scope of the problem
}

\author{
IN BRIEF \\ - Highlights the increasing emergence of \\ peri-implant diseases, particularly peri- \\ implantitis, which threaten the survival \\ of both the implant and the supported \\ restorations. \\ - Discusses the aetiology, prevalence and \\ diagnostic features of peri-implantitis.
}

A. Alani, ${ }^{* 1}$ M. Kelleher ${ }^{1}$ and K. Bishop ${ }^{2}$

Peri-implantitis is a relatively new disease process that results in gingival inflammation and bone loss around implants. The associated co-morbidities are significant due to the relative financial and biological costs of implant provision. At the current time there is a lack of consensus on the exact aetiology and subsequent pathological process, although this is largely thought to be infective in nature. Unfortunately, due to the relatively new nature of this problem, evidence is continually emerging on diagnosis, prevention, prevalence and incidence. This first part of three reviews will discuss these points and will act as an introduction to part two on prevention and part three on management of this now significant dental pathology.

\section{INTRODUCTION}

Dental implants, when successfully planned and maintained, provide a contemporary option for the rehabilitation of the edentate and partially dentate patient. The implant retained prosthesis was initially pioneered by Branemark and his team of specialists with defined protocols in controlled settings undertaken on selected patients. ${ }^{1}$ Prior to these results being published, predictable integration was a phenomenon that was considered to be somewhat 'hit and miss.'2 During an extraordinary meeting in Toronto in 1982 Branemark and his team publicised their long-term results. Since then implant placement has increased exponentially due to greater availability, knowledge, research and individual patients or their dentists desiring a 'fixed rather than a removable restoration' or a better retained removable prosthesis., ${ }^{3,4}$ This increase in demand has led to implants now being available to patients in both the primary and secondary settings. As such, the clinical reasoning for the utilisation of implants can vary, as well as the skill set of the various clinicians in both planning, delivering and maintenance of implant restorations ${ }^{5,6}$ However, it is well recognised that early adopters of new technologies and less experienced clinicians are more likely to encounter complications. ${ }^{7}$

'Department of Restorative Dentistry, Kings College Hospital, Denmark Hill, London, SE5 9RS;

${ }^{2}$ Department of Restorative Dentistry, Maxillofacial Unit, Morriston Hospital, Swansea, SA6 6NL

${ }^{*}$ Correspondence to: Aws Alani

E-mail: awsalani@hotmail.com

\section{Refereed Paper}

Accepted 10 June 2014

DOI: 10.1038/sj.bdj.2014.808

${ }^{\circ}$ British Dental Journal 2014; 217: 281-287

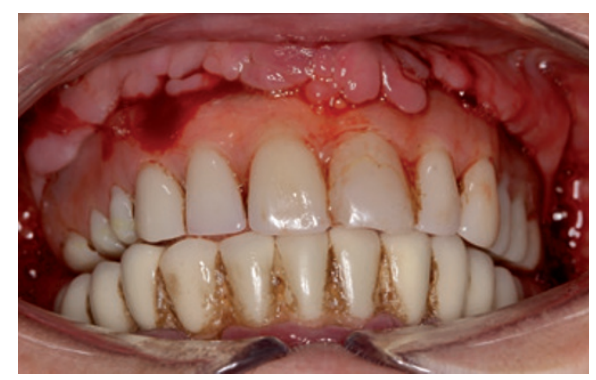

Fig. 1a This patient was provided with full arch implant retained bridges privately approximately five years ago to replace her natural dentition. The previous dentition was otherwise intact and asymptomatic. On presentation she was spontaneously bleeding from all implant sites with pain and suppuration from the upper left side. Halitosis was also a significant complaint

The increase in the demand for implants by society at large and the wider range of clinicians providing this care has resulted in the number of dental implants placed increasing significantly over the last 20 years and this is likely to continue. ${ }^{8}$ In the US alone 5.5 million implants were placed in $2006 .{ }^{9}$ The dental implant market in the US is projected to reach $\$ 5$ billion by $2018 .^{9}$ The increasing worldwide volume of implants placed is associated with a large and growing need for longer term maintenance as the biological and mechanical complications associated with implant therapy become more apparent. ${ }^{10,11}$

Problems can range from restoration renewal to the need for peri-implant tissue maintenance. ${ }^{12}$ Where patients are provided with implants without due consideration for this long-term support there may be significant financial, biological or legal consequences. ${ }^{13,14}$ Many patients may have the financial capability to have implants

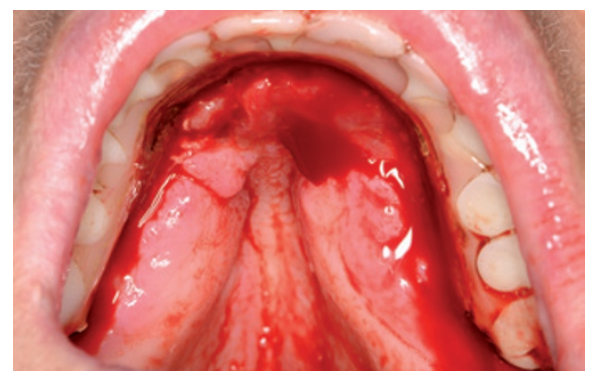

Fig. 1b On further examination soft tissue swellings were present palatally on both right and left hand sides. Due to the design of the prosthesis self-administered plaque control was difficult to achieve

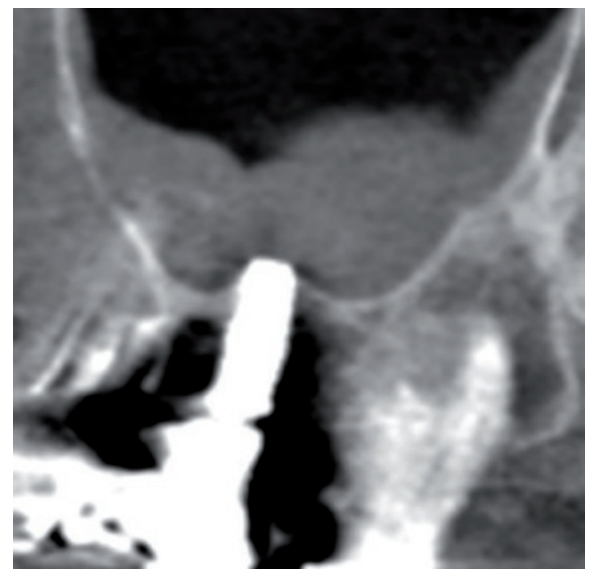

Fig. 1c Cone beam computed tomography examination revealed obvious bone loss on all implants placed. The patient required removal of the implants and complete denture provision

placed and restored when they are economically active but the ongoing costs may not be readily apparent to them, especially where these were not clearly defined or documented adequately before start of treatment (Fig. 1). Other patients may be under 
the wrong impression that implants always provide greater longevity than natural tooth tissue (Fig. 2a and 2b).

It is becoming increasingly apparent that the probability of complications with implants is increasing even if planning and delivery is appropriate. ${ }^{10,12}$ In addition patients who require implant therapy are likely to have lost teeth previously through plaque-related processes such as periodontal disease..$^{15}$ This susceptibility continues with the osseointegrated restorations and as such contributes to the risk of future complications. ${ }^{16}$

This series of papers will focus on the increasing emergence of peri-implant diseases, particularly peri-implantitis, which represent a significant co-morbidity to implant provision and threaten the survival of both the implant and the supported restorations.

\section{TERMINOLOGY AND DEFINITIONS}

Peri-implant mucositis has similar characteristics to gingivitis and has been defined as a reversible inflammatory lesion affecting the soft tissue in the area immediately around implants but not affecting the surrounding bone (Fig. 3). ${ }^{17}$

Peri-implantitis has been defined as an inflammatory lesion causing crestal bone loss and soft tissue inflammation which can present with bleeding on probing and suppuration (Fig. 4). ${ }^{17}$

Mombelli first described peri-implantitis when he and co-workers compared the microbiological features of implants considered to be successful and those that were 'failing' resulting in bone loss. ${ }^{18}$ Even at this early stage this study illustrated how poor oral hygiene and uncleansable suprastructures increased the likelihood of a pathogenic biofilm. ${ }^{18}$

One relatively new manifestation of periimplantitis is apical (or retrograde) periimplantitis which presents at the apex of root formed endosteal implants (Fig. 5). ${ }^{19}$

\section{DIAGNOSTIC FEATURES OF PERI-IMPLANTITIS}

\section{Clinical features}

\section{Appearance}

Peri-implant lesions are often asymptomatic in their early stages and can present as a chance finding at recall. In such presentations, the peri-implant soft tissues are usually inflamed, presenting with bleeding on probing, consistent with a diagnosis of peri-implant mucositis. Inflammation of the gingival cuff may not, however, always be present but gingival enlargement can develop if implants are located in an area

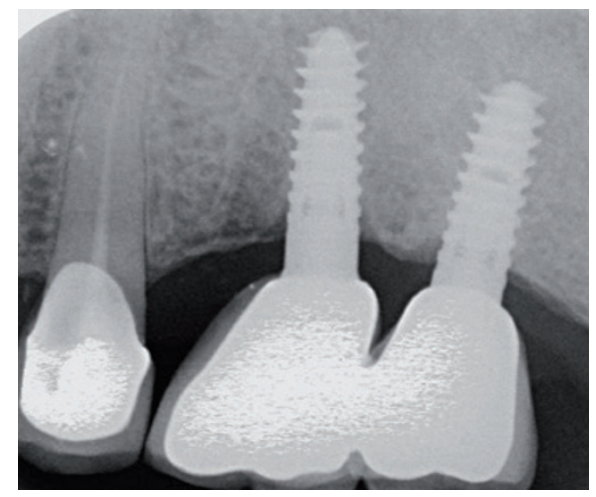

Fig. 2a Long cone periapical of the upper left quadrant in a patient presenting complaining of pain from the 25 . Despite requiring root canal re-treatment and a new coronal restoration the tooth was later extracted in favour of a third implant and a new bridge

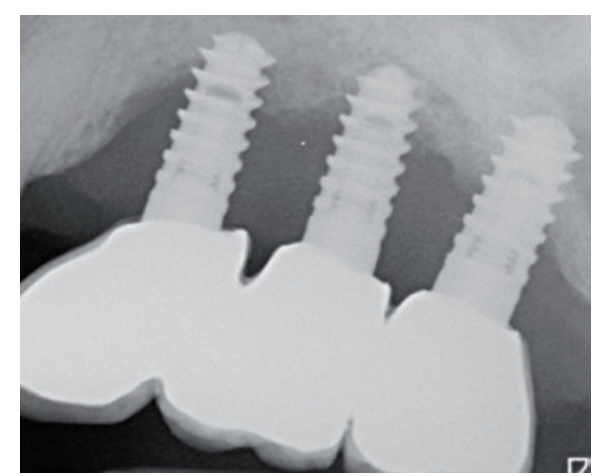

Fig. $2 b$ Long cone periapical radiograph of the same site taken three years later. Severe bone loss as a result of peri-implantitis was evident. Despite efforts to treat the implants all three fixtures were explanted and the patient provided with a partial denture

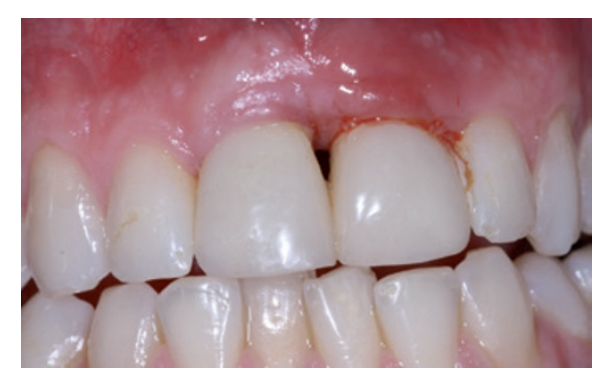

Fig. 3 Peri-implant mucositis localised to the implant in the 21 site. The implant in the 11 site was otherwise inflammation free. The 21 exhibited bleeding on probing but no signs of bone loss and required improvement in hygiene measures which resulted in improvement in signs and symptoms

of non-keratinised mucosa or if the restoration is removable (Fig. 6). Recession may also be present in combination with exposed implant threads. Where the gingiva is thin, a blue hue may be present due to shine through of the underlying metal implant.

\section{Probing}

Peri-implant probing is important for both diagnosing peri-implantitis and monitoring

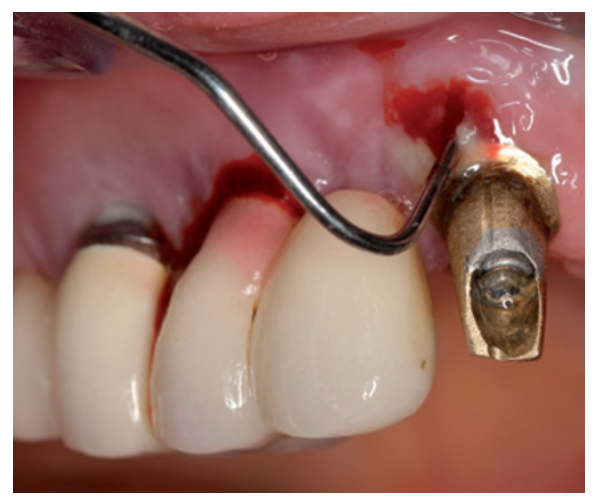

Fig. 4 Peri-implantitis detected on implants in the 11, 13 and 14 sites. Probing on the 11 implant was easier to achieve than the 13 and 14 due to the removal of the crown which impeded optimal probe angulation. The size of pocket was not fully appreciated as this was deeper than the size of the probe. Marked pus and bleeding was present throughout probing making recording of depths difficult

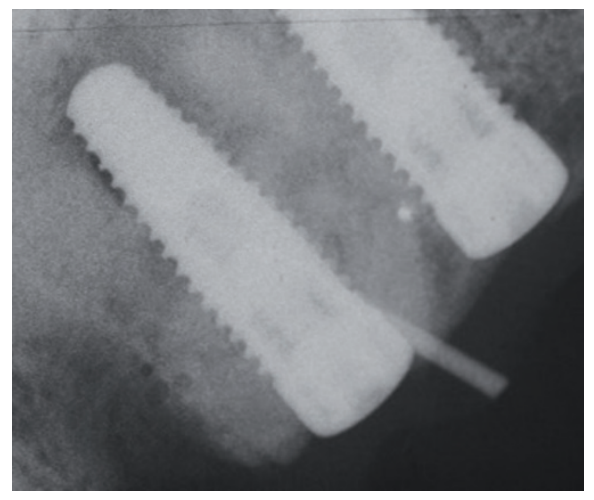

Fig. 5 Long cone periapical of an implant presenting with a buccal discharging sinus. A gutta percha point was placed within the sinus which coincided with an implant apical radiolucency. Periapical peri-implantitis was diagnosed and local surgical debridement of this site was achieved and resulted in cessation of some of the patients symptoms



Fig. 6 Peri-implantitis on an implant in the $\mathbf{2 7}$ site. Due to the buccal position of the fixture the buccal aspect of the implant was adjacent to mobile non-keratinised tissue. A significant degree of plaque and bleeding was detected

disease progression (Figs 4 and 6). ${ }^{20}$ Similarly to teeth a $0.25 \mathrm{Ncm}$ probing force has been recommended. ${ }^{21}$ There have been concerns that probing force similar to that for teeth may result in false positive readings for bleeding on probing or permanent damage of the tissues. ${ }^{22}$ This has since been 


\section{Table 1 Recommendations on probing}

Where access to the implant is not compromised the use of a metal probe is advised. Where the suprastructure is bulky and removal is not readily achievable then a plastic probe maybe used to circumnavigate the attached restoration. Ideally the probe should pass parallel to the long axis of the implant for accurate measurements.

Four points of probing should be obtained; two buccally and two lingually/palatally.

Ensure measurements are taken along the long axis of the implant and not the restoration.

Probing force should be no different than that for teeth-namely $0.25 \mathrm{Ncm}$.

Bleeding and suppuration on probing should be noted.

A fixed reference point should be utilised. This may either be the abutment or crown margin.

discounted and a probing force of $0.25 \mathrm{Ncm}$ is now recommended. The epithelium around implants after probing has been shown to heal within five days. ${ }^{23}$

Peri-implant probing should be performed to determine the location of the base of a pocket relative to a known and documented fixed landmark on the implant or its suprastructure. ${ }^{24}$ Probe penetration varies with the condition of the peri-implant tissues. In health and mucositis, the presence of a soft tissue collar prevents the probe from reaching the alveolar crest. ${ }^{25}$ In contrast probe penetration has been shown to reach the alveolar bone level in peri-implantitis. ${ }^{25}$

Probing error has been shown to be greater around implants with peri-implantitis than those with mucositis or in health. ${ }^{25}$ Because of this phenomenon standardisation of probing around implants is important for accuracy and the detection of any inflammatory changes. Measures such as reducing probing force to $0.25 \mathrm{Ncm}$ and the recording of probing points and angulations in relation to the restoration might improve repeatability and accuracy.

Probing around implants often tends to be more difficult than around teeth due to the need to navigate around the implant suprastructure. Where the restoration is bulky, reproducible probing depths may only be possible if the restoration is removed to assist direct visual examination. One suggestion has been to use plastic probes (TPS or WHO 621) due to their superior flexibility and ability to navigate around the implant suprastructure. ${ }^{20}$ The clinical process of identifying the base of the pocket with certainty can also be difficult. If the apex of the probe engages a thread this may be mistaken for the bottom of the defect. Although the use of a plastic probe has advantages, metal probes are still the first choice for probing. ${ }^{26,27}$
Interpretation of probing depths requires caution. Deeply located implants may have probing depths of $5 \mathrm{~mm}$ or greater but remain clinically healthy. Pathologic probing profiles around implants are usually consistent circumferentially around the fixtures.

The need to interpret probing profiles and more importantly their changes over time seem to provide the best information on disease development and progression..$^{28,29}$ These progressive changes need to be differentiated from any expected bone remodelling post implant placement. ${ }^{21}$ Recommendations for probing are given in (Table 1).

\section{Bleeding on probing}

Bleeding on probing represents the inflammatory response of tissues to the presence of a biofilm. Bleeding on probing around implants has been shown to be a significant predictor for disease presence. ${ }^{30,31}$ Indeed the presence of bleeding on probing is a better predictor of peri-implant disease than analogous periodontal disease. ${ }^{30,31}$ As such detection of bleeding on probing or periimplant mucositis should be a prompt for the increased reinforcement of self-directed oral hygiene measures as well as supportive periodontal treatment. This increased self and professionally directed maintenance is likely to be crucial in the preventing progression to peri-implantitis.

\section{Suppuration}

Suppuration indicates active peri-implantitis and is likely to be associated with bone loss and future implant failure if no active preventive treatment is instigated.

\section{Percussion}

Tenderness to percussion can be detected in peri-implantitis and also the rarer presentation of retrograde peri-implantitis. Implants should be percussed in lateral and apical directions to aid diagnosis. The percussion tone can also be noted since where significant bone loss has occurred the tone can often be duller than the normal high pitch associated with implants in health. However, this finding must be treated with caution due to the lack of robust evidence to support this association.

\section{Mobility}

Mobility is a poor indicator for peri-implantitis progression and is only really relevant where the disease has progressed to the extent that implant removal is indicated. ${ }^{21}$ Where extensive reconstructions are supported by a number of implants there may be a need to deconstruct the bridgework, or bar, to fully assess the presence of mobility of individual units. Even in cases of advanced bone loss implants may remain immobile despite marked tissue loss due to partial loss of integration.

Delineation between true mobility of the implant and that of its supra structure is also required. For example, detection of mobility of an implant retained crown can be performed by applying rotational movement to the crown between forefinger and thumb as opposed to a bucco-palatal direction. This is due to the orientation of the threads making rotational movement more discernible.

\section{Resonance frequency analysis}

Resonance frequency analysis is a method of recording micro-motion of an implant by way of implant stability quotient (ISQ). A stable integrated implant has an ISQ value of approximately $70 .^{32}$ This method is utilised to measure stability once integration is completed and before restoration. One recent study measured resonance frequency as a means of measuring success for surgical treatment of peri-implantitis. ${ }^{32}$ As yet the ISQ number has not been utilised for the monitoring or diagnosis of peri-implantitis.

\section{Retrograde peri-implantitis}

Where retrograde peri-implantitis presents the gingival margin may appear to be disease free without the presence of marginal implant bone loss. ${ }^{33}$ Instead the lesion may present clinically as a sinus tract or a swelling coinciding with the apical portion of the implant. Tenderness over the apical portion of the implant may also be present.

\section{Radiographic features}

Good quality radiographic examination is valuable in the diagnosis and monitoring of peri-implantitis. Radiographs taken once the restorations are definitively placed should be adequate to provide a baseline for future reference and help to confirm optimal restoration seating (Figs 7a and b). Marginal bone changes during the first year of restoration maybe related to physiological bone remodelling and establishment of biologic width, and should not be confused with periimplant disease. ${ }^{34}$

The baseline radiograph may be repeated after the first year in function to assess the stability of bone support, or in cases where any clinical signs may indicate incipient pathology. Any further radiographic exposures should be done on the basis of need and should be based on significant changes in the clinical picture and not just performed to follow any arbitrary protocol.

Optimal beam angulation will allow threads to be recorded and provide additional information on disease progression. ${ }^{35}$ Indeed parallel angulation will result in thread sharpness on both sides of the implant. ${ }^{36}$ 
Consistent angulations can be challenging where restorations are particularly bulky. Implants that are often longer than adjacent teeth and their restoration can be significantly angled away from the long axis of the implant (Fig. 8).

Radiographically, peri-implantitis lesions can vary in their presentations. Where the alveolus is wide bucco-lingually or buccopalatally they can present as a saucer or funnel outline with mesial and distal portions of similar shape or near equal extent (Fig. 9). Where the alveolar ridge is thin or just wide enough to accommodate the implant the bone loss often appears to be more horizontal in nature.

Radiographs have their limitations when interpreting a three-dimensional pathologic process. For example, interproximal bone levels may appear to be intact radiographically but clinically a significant peri-implantitis lesion can be present, especially on the buccal aspect. The radiopacity of implants when compared to teeth may reduce the sensitivity of radiographs when attempting to detect periimplant problems. Advice on radiographic imaging for implants is given in Table 2.

\section{Advanced imaging}

Digital subtraction radiography can be utilised to detect bone density changes adjacent to implants. ${ }^{37}$ Functional loading has been shown to result in bone density increase whereas peri-implant infection results in a decrease. ${ }^{37}$ This tool may provide adequately trained clinicians with the ability to detect early changes in bone which would otherwise be difficult to detect using conventional techniques. ${ }^{38}$

The use of cone beam technology in the diagnosis and assessment of biological complications involving encroachment on structures such as the inferior dental canal and the maxillary sinus is well established. Conversely, cone beam imaging in the diagnosis and assessment of peri-implantitis lesions is less common (Fig. 1c). ${ }^{39}$ At present there is only one pilot study illustrating the use of cone beam computed tomography in the assessment peri-implantitis defects. ${ }^{39}$ As such the evidence is, at the current time, insufficient to advocate its routine use in diagnosis. Moreover the increased radiological exposure may not provide significantly greater information that may affect treatment decisions.

\section{AETIOLOGY AND EPIDEMIOLOGY}

\section{Aetiology of peri-implant diseases}

There is still some considerable conjecture with regards to the true aetiology of peri-implantitis. ${ }^{40}$ Recently there has been

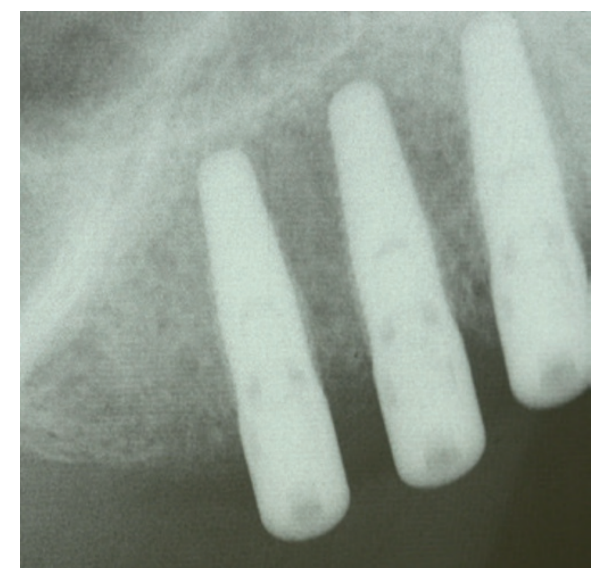

Fig. 7a Long cone periapical of implants in the 13,14, and 15 sites. Due to poor angulation the position of the alveolar crest relative to the implants could not be delineated. Due to the poor angulation the implant threads could not be identified

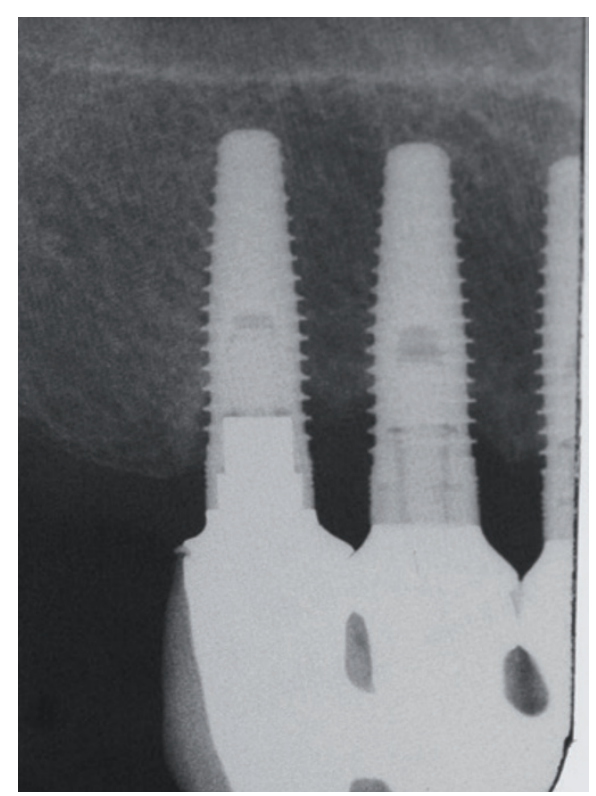

Fig. 7b Long cone periapical post restoration. With optimal paralleling technique the alveolar crest could be identified as well as the position of bone relative to the threads of the implant

speculation that a peri-implantitis infection is actually a secondary manifestation of an exaggerated foreign body reaction to the implant itself. ${ }^{41}$ The same group also identified corrosion of the implant as a potential risk factor for the development of periimplantitis. ${ }^{42}$ Greater research in aetiological factors other than biofilm development seems to be required.

However, the development of a biofilm is considered by many workers as a key factor in the development of peri-implantitis. ${ }^{43}$ Biofilm development may become more likely once any marginal bone loss occurs whether this be pathological or physiological. As such it can be debated that biofilm development is a secondary, as opposed to a

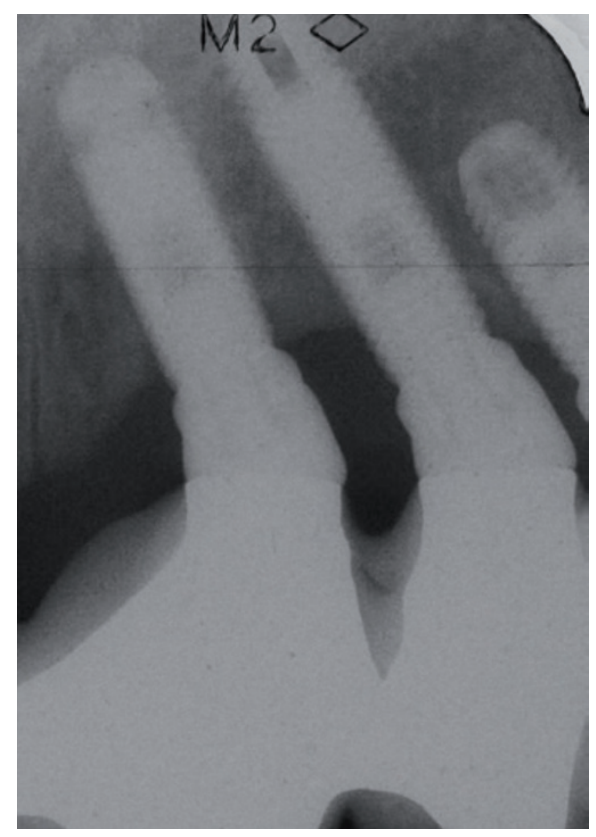

Fig. 8 Long cone periapical of implants retaining bridgework in the 22, 23 and 24 sites. Due to the gross difference in angulation between the long axis of the crowns and implants optimal radiographic examination was difficult to achieve without the need for multiple radiographs

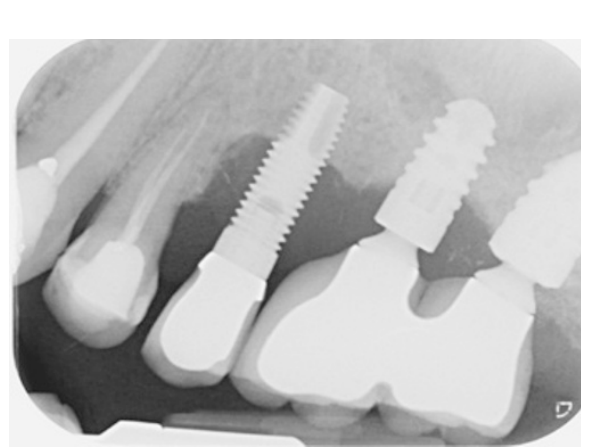

Fig. 9 Dental panoramic tomograph illustrating localised peri-implantitis on the implant in the 31 site. Note the funnel shaped nature of the radiolucency which is virtually symmetrical mesially and distally

\section{Table 2 Recommendations on radiography}

Utilisation of perpendicular beam angulation to the axial inclination of the implant and not of the associated restoration which maybe angled differently.

Where possible attempts at maintaining reproducible beam angulations between separate time points aides disease diagnosis and monitoring.

Once definitive restorations are torqued or cemented an initial radiograph should be taken. Ideally long cone peri-apical views provide the best clinical picture. Dental tomograms may be less beneficial due to decreased clarity especially where implant angulations are outwith of the focal trough.

At a one year review the initial radiographic exam should be repeated and compared to the initial examination and compared to illustrate biological width development or indeed presence of peri-implantitis.

Future radiographic examinations may be considered when clinical signs and symptoms elicit the presence of a pathology requiring further investigation. 


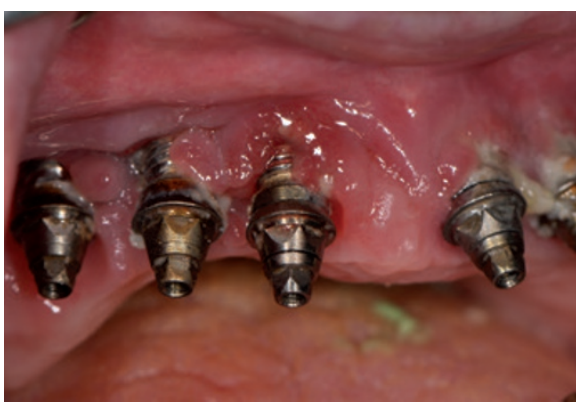

Fig. 10 Peri-implantitis on all maxillary fixtures placed for purposes of a fixed bridge. The bridge design inhibited effective cleaning and the implants subsequently became populated plaque resulting in peri-implantitis

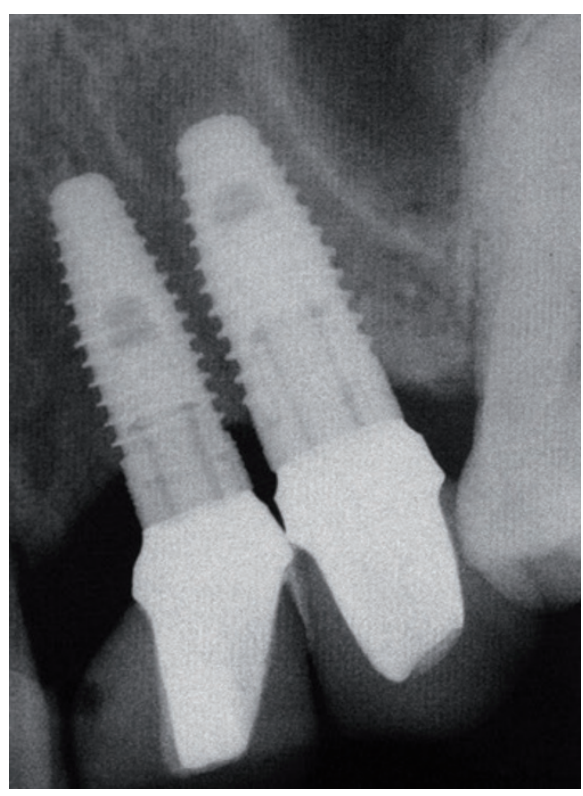

Fig. 11 Implants placed in close proximity in the 23, 24 site. Bone loss was noted between the fixtures. Provision of crowns was difficult to achieve as was professional and self administered interproximal cleaning

primary, aetiological factor for peri-implant bone loss (Fig. 10). ${ }^{44}$

Teeth and implants are anatomically different and as such so is the process of biofilm development. Teeth have transeptal or dentogingival fibres (Sharpey's fibres) that insert into cementum and tend to form a seal against bacteria in health. These are absent in implants and the fibres that exist are largely circumferential in nature. ${ }^{45}$ Once an abutment is connected to the implant the microflora that establishes in the peri-implant sulcus is nearly identical to that found on adjacent teeth. ${ }^{46}$ Progression to bacterial population of the implant surface may result from epithelial ulceration with disruption of peri-implant connective tissue adhesion leading to biofilm establishment there. ${ }^{45}$

Factors that are likely to influence the nature of the biofilm and its establishment include surface roughness, composition, and the thread profile. Implants with rougher surfaces and more aggressive thread pitches are likely to develop a biofilm that is more robust and difficult to remove. ${ }^{47-49}$ Unfortunately, these features are designed to improve osseointegration but perversely also seem to promote biofilm formation. As such a need for greater quality research into the effect of surface characteristics on periimplantitis development has been highlighted by an international consensus group. ${ }^{50} \mathrm{~A}$ possible innovative approach to peri-implantitis maybe the creation of a surface which is osseointegrative but concurrently antimicrobial when exposed to the oral environment. ${ }^{51}$

Once a biofilm becomes adequately established inflammation of the circumferential soft tissue can result in peri-implant mucositis. $^{52}$ Detecting progression from biofilm development to peri-implant mucositis is crucial as mucositis is readily treatable with oral hygiene measures and biofilm disruption. ${ }^{53}$ If this microbial colonisation is prolonged, an inflammatory infiltrate forms in response which results in the establishment of a periimplantitis lesion. ${ }^{54}$ However the progression from mucositis to peri-implantitis is not automatic and as such patients may present with erythematous tissues without associated bone loss. In cases where progression does occur the local host response mediates bone resorption in a similar way to periodontitis, resulting in decreased bone implant contact over time. There have been suggestions that peri-implantitis progresses at a greater rate than periodontitis due a variety of histological factors. ${ }^{55}$ Where periodontal and periimplantitis lesions are compared a protective tissue capsule, which serves to self-limit the lesion, is present in periodontitis but absent in peri-implantitis. ${ }^{45}$ As a result the apical extent of the lesion is more pronounced in periimplantitis than periodontitis. Peri-implantitis lesions have been shown to exhibit signs of acute inflammation with proportionally greater amounts of inflammatory mediators and resorbing osteoclasts lining the crestal bone..$^{55}$ It seems that the pathology associated with peri-implantitis is more aggressive and rapid and so can develop unchecked due to these characteristics.

This is reflected in studies examining surface roughness and the progression of peri-implantitis; those implant surfaces with smoother surfaces exhibited less progression of peri-implantitis than those with greater surface area and geometries. ${ }^{56}$ As such surface area and geometry of fixtures plays a significant role in the osseointegration process but conversely appears to result in faster progression of peri-implantitis if and once the disease process has been initiated. ${ }^{57}$

Sand-blasted and acid-etched surfaces (SLA) appear to develop mature biofilms quicker than machined and modified acidetched implants. ${ }^{58}$ Indeed the slower the biofilm formation the greater the likelihood of the presence of immature biofilm which is easier to remove. ${ }^{58}$ SLA surfaces appear to exhibit the highest values for bacterial colonisation and biofilm maturation. ${ }^{59}$ An assessment of the surface characteristics of the implant may be considered prudent where published research indicates that certain implant types are likely to harbour more virulent biofilms which may worsen prognosis. ${ }^{59}$ Communication of these issues to the patient before the start of any treatment is likely to aid patient understanding of prognostic factors and help to inform the consent process.

The exact aetiology of apical (or retrograde) peri-implantitis is unclear but it is thought to be related either to the overheating of bone apically during implant placement, contamination of the implant surface during instrumentation or pre-existing disease at or close to the implant site for example, residual apical pathology from a previously extracted tooth, residual root fragments, or close proximity to an infected maxillary sinus. ${ }^{59-61}$ True apical peri-implantitis needs to be distinguished from vertical over-preparation of the implant site. ${ }^{62}$

\section{Differential diagnosis}

Bone loss around implants may occur due to reasons other than biofilm development. Once an implant is restored a period of bone remodelling is likely to occur which may result in the appearance of bone loss without infection. ${ }^{63}$ This establishment of the implant biologic width happens over the course of the first year after restoration after which the bone level stabilises. ${ }^{64}$ The rate at which bone stabilises varies between different implant systems. ${ }^{64}$

Soft tissue manipulation techniques designed to contour restorations to preferentially mould gingival tissue can also result in bone remodelling in a similar way. ${ }^{65}$

Implant positioning can also effect the bone remodelling, If implants are placed too close together then the risk of physiological bone loss may increase (Fig. 11). ${ }^{66} \mathrm{~A}$ similar situation may arise with implants placed too deeply resulting in bone loss from bone adjacent to the submucosal component of the restoration. ${ }^{67}$

Gingival biotype can also influence physiological bone remodelling around implants. Thick biotypes have a lesser propensity to loose marginal bone than thinner types. ${ }^{68}$

\section{Prevalence and incidence}

There is limited evidence on the prevalence of peri-implant diseases, with less available on its incidence. A study by Fransson et al. 
has shown that peri-implant mucositis is present in $28 \%$ of subjects having at least one implant affected by peri-implantitis. ${ }^{69}$ This study examined 662 patients with implants placed between 5-23 years. Of the 1,070 implants examined, 40\% presented with bone loss associated with peri-implantitis. Interestingly the anterior mandible was the most commonly affected site. ${ }^{69}$

In contrast recent research findings utilising meta-analysis shows 19\% of patients and 10\% of implants were diagnosed with peri-implantitis. ${ }^{70}$ The most recent research by way of systematic review of nine studies examining 6,283 implants in 1,497 subjects found the frequency of peri-implant mucositis to be present in $63.4 \%$ of participants with peri-implantitis found in $19 \% .^{71}$

The above studies may, however, be an underestimation of the true prevalence of the disease. ${ }^{72,73}$ In a systematic review examining quality of studies investigating periimplant disease the majority of studies on prevalence did not state the applied study design, describe any effort to address sources of bias nor explain how missing data was addressed. ${ }^{74}$ Reasons for this apparent bias and underestimation may be numerous. ${ }^{74-76}$ Other aspects are linked at the patient level where the features of the disease mean that it is under reported by patients. For example, peri-implantitis might provide less symptoms than the periodontitis and may become mobile only at the terminal stage.

The literature examining the incidence of peri-implantitis is more sparse. A study by Renvert and colleagues examined the incidence of peri-implantitis over a 13-year period. ${ }^{77}$ The incidence of peri-implantitis development between years 1 and 7 varied between $26.2 \%$ and $30.4 \%$ depending on the implant system. This fell to between 7.1\% and $11.5 \%$ between years 7 and 13 again respective to the implant system. ${ }^{77}$ The difference between implant systems or surfaces was not, however, found to be significant. ${ }^{78}$

The risk of peri-implantitis in the early years after placement is supported by a retrospective study of 281 patients over a period of nine months to 13 years by Charalampakis and colleagues. ${ }^{78}$ This study examined patients with peri-implantitis and found that, sadly, $91 \%$ of patients examined had pus, bleeding, bone loss of greater than one third of the implant or probing depths of $7 \mathrm{~mm}$ or greater. ${ }^{78}$ In $43 \%$ of patients peri-implantitis developed early with fixtures having been in function for less than four years. ${ }^{78}$ Although evidence is limited and requires further clarification it seems that the risk of peri-implantitis is present soon after implant placement and with incidence possibly decreasing with time. ${ }^{77}$
Despite a high reported incidence and prevalence from a limited research base there also seems to be a cohort of patients who may present with peri-implant mucositis but are resistant to further progression of the disease despite the presence of a virulent biofilm. ${ }^{69}$

\section{CONCLUSION}

The increasing number of implants being placed by a wider range of clinicians and in patients with varying demand and associated risks may lead towards increased prevalence and incidence of peri-implantitis.

Where peri-implantitis lesions progress unchecked the need for implant removal may become unavoidable. Removal of the entire implant, termed explantation, often leaves a sizeable defect, can be traumatic and can result in marked soft tissue changes leaving an edentate site that is more difficult to manage than previously. Indeed implants placed in previously failed sites have a decreased chance of survival. ${ }^{79}$ As such, prevention of peri-implantitis is a key factor in patients where implants are being planned.

The next part in this series of papers will examine techniques in preventing the development of peri-implantitis.

1. Adell R, Lekholm U, Rockler B, Brånemark PI. A 15 -year study of osseointegrated implants in the treatment of the edentulous jaw. Int J Oral Surg 1981; 10: 387-416.

2. Cherchève R. The philosophies which governed the origin, development and present-day use of endosseous dental implants. J Oral Implant Transplant Surg 1966; 12: 28-34.

3. Zarb G A, Schmitt A. Implant prosthodontics at the University of Toronto. Univ Tor Dent J 1988; 1: 25-29.

4. Azarpazhooh A, Dao T, Figueiredo R, Krahn M, Friedman S. A survey of dentists' preferences for the treatment of teeth with apical periodontitis. J Endod 2013; 39: 1226-1233.

5. Al-Khabbaz A K, Griffin T J, Al-Shammari K F. Assessment of pain associated with the surgical placement of dental implants. J Periodonto/ 2007; 78: 239-246.

6. Cushen S E, Turkyilmaz I. Impact of operator experience on the accuracy of implant placement with stereolithographic surgical templates: an in vitro study. J Prosthet Dent 2013; 109: 248-254.

7. Esposito M, Hirsch J M, Lekholm U, Thomsen P. Biological factors contributing to failures of osseointegrated oral implants. (II). Etiopathogenesis. Eur J Oral Sci 1998; 106: 721-764.

8. Armas J, Culshaw S, Savarrio L. Treatment of periimplant diseases: a review of the literature and protocol proposal. Dent Update 2013; 40: 472-474, 476-8, 480.

9. American Academy of Implant Dentistry. http://aaid. com/about/Press_Room/Dental_Implants_FAQ.html

10. Gervais M J, Wilson PR. A rationale for retrievability of fixed, implant-supported prostheses: a complication-based analysis. Int J Prosthodont 2007; 20: 13-24.

11. Pjetursson B E, Thoma D, Jung R, Zwahlen M, Zembic A. A systematic review of the survival and complication rates of implant-supported fixed dental prostheses (FDPs) after a mean observation period of at least 5 years. Clin Oral Implants Res 2012; Suppl 6: 22-38.

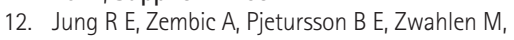
Thoma D S. Systematic review of the survival rate and the incidence of biological, technical, and aesthetic complications of single crowns on implants reported in longitudinal studies with a mean follow-up of 5 years. Clin Oral Implants Res 2012; Suppl 6: 2-21.

13. Incici $E$, Matuliene G, Hüsler J, Salvi G E, Pjetursson $B, B r a ̈ g g e r ~ U$. Cumulative costs for the prosthetic reconstructions and maintenance in young adult patients with birth defects affecting the formation of teeth. Clin Oral Implants Res 2009; 20: 715-721.

14. Albrektsson T, Donos N; Working Group 1. Implant survival and complications. The Third EAO consensus conference 2012. Clin Oral Implants Res 2012; 23 Suppl 6: 63-65.

15. Schou S, Holmstrup P, Worthington H V, Esposito M. Outcome of implant therapy in patients with previous tooth loss due to periodontitis. Clin Oral Implants Res 2006; Suppl 2: 104-123.

16. Gatti C, Gatti F, Chiapasco M, Esposito M. Outcome of dental implants in partially edentulous patients with and without a history of periodontitis: a 5 -year interim analysis of a cohort study. Eur J Oral Implantol 2008; 1: 45-51.

17. Zitzmann N U, Berglundh T. Definition and prevalence of peri-implant diseases. J Clin Periodontol 2008; 35: 286-291.

18. Mombelli A, van Oosten M A, Schurch E Jr, Land N P. The microbiota associated with successful or failing osseointegrated titanium implants. Oral Microbiol Immunol 1987: 2: 145-151.

19. Bretz W A, Matuck AN, de Oliveira G, Moretti A J, Bretz W A. Treatment of retrograde peri-implantitis: clinical report. Implant Dent 1997; 6: 287-290.

20. Heasman P, Esmail Z, Barclay C. Peri-implant diseases. Dent Update 2010; 37: 511-512; 514-516.

21. Heitz-Mayfield $\sqcup$. Peri-implant diseases: diagnosis and risk indicators. J Clin Periodontol 2008; 35: 292-304.

22. Gerber J A, Tan W C, Balmer T E, Salvi G E, Lang N P. Bleeding on probing and pocket probing depth in relation to probing pressure and mucosal health around oral implants. Clin Oral Implants Res 2009; 20: 75-78.

23. Etter T H, Håkanson I, Lang N P, Trejo P M, Caffesse $R$ G. Healing after standardized clinical probing of the perlimplant soft tissue seal: a histomorphometric study in dogs. Clin Oral Implants Res 2002; 13: $571-580$.

24. Todescan S, Lavigne S, Kelekis-Cholakis A. Guidance for the maintenance care of dental implants: clinical review. J Can Dent Assoc 2012; 78: c107.

25. Lang N P, Wetzel A C, Stich H, Caffesse R G. Histologic probe penetration in healthy and inflamed peri-implant tissues. Clin Oral Implants Res 1994; 5: 191-201.

26. Lindhe J, Meyle J; Group D of European Workshop on Periodontology. Peri-implant diseases: Consensus Report of the Sixth European Workshop on Periodontology. J Clin Periodontol 2008; 35: 282-285.

27. Lang N P, Berglundh T; Working group 4 of Seventh European Workshop on Periodontology. Periimplant diseases: where are we now?-Consensus of the Seventh European Workshop on Periodontology. J Clin Periodontol 2011; 11: 178-181.

28. Madi M, Zakaria O, Noritake K, Fuji M, Kasugai S. Peri-implantitis progression around thin sputtered hydroxyapatite-coated implants: clinical and radiographic evaluation in dogs. Int J Oral Maxillofac Implants 2013; 28: 701-709.

29. Martins M C, Shibli J A, Abi-Rached R S, Marcantonio E Jr. Progression of experimental chronic peri-implantitis in dogs: clinical and radiographic evaluation. J Periodonto/ 2005; 76: 1367-1373.

30. Luterbacher S, Mayfield L, Brägger U, Lang N P. Diagnostic characteristics of clinical and microbiological tests for monitoring periodontal and periimplant mucosal tissue conditions during supportive periodontal therapy (SPT). Clin Oral Implants Res 2000; 11: 521-529.

31. Jepsen $S$, Rühling $A$, Jepsen $K$, Ohlenbusch $B$, Albers $H$ K. Progressive peri-implantitis. Incidence and prediction of peri-implant attachment loss. Clin Oral Implants Res 1996; 7: 133-142.

32. Wohlfahrt J C, Lyngstadaas S P, Rønold H J, Saxegaard E, Ellingsen J E, Karlsson S, Aass A M. 
Porous titanium granules in the surgical treatment of peri-implant osseous defects: a randomized clinical trial. Int J Oral Maxillofac Implants 2012; 27: 401-410.

33. Dahlin C, Nikfarid H, Alsén B, Kashani H. Apical peri-implantitis: possible predisposing factors, case reports, and surgical treatment suggestions. Clin Implant Dent Relat Res 2009; 11: 222-227.

34. Firme C T, Vettore M V, Melo M, Vidigal GM Jr. Peri-implant Bone Loss Around Single and Multiple Prostheses: Systematic Review and Meta-Analysis. Int J Oral Maxillofac Implants 2014; 29: 79-87.

35. Floyd P, Palmer P, Palmer R. Radiographic techniques. Br Dent J 1999; 187: 359-365.

36. Mattheos $\mathrm{N}$, Janda M S. Exotic encounters with dental implants: managing complications with unidentified systems. Aust Dent J 2012; 57: 236-242.

37. Brägger U, Bürgin W, Lang N P, Buser D. Digital subtraction radiography for the assessment of changes in peri-implant bone density. Int J Oral Maxillofac Implants 1991; 6: 160-166.

38. Wakoh M, Nishikawa $K$, Otonari T, Yamamoto $M$ Harada T, Sano T, Yajima Y, Ooguro T. Digital subtraction technique for evaluation of peri-implant bone change in digital dental imaging. Bull Tokyo Dent Coll 2006; 47: 57-64.

39. Golubovic V, Mihatovic I, Becker J, Schwarz F. Accuracy of cone-beam computed tomography to assess the configuration and extent of ligatureinduced peri-implantitis defects. A pilot study. Oral Maxillofac Surg 2012; 16: 349-354.

40. Pesce P, Menini M, Tealdo T, Bevilacqua M, Pera F, Pera P. Peri-implantitis: a systematic review of recently published papers. Int J Prosthodont 2014; 27: 15-25.

41. Albrektsson $T$, Dahlin $C_{\text {, Jemt }} T_{\text {, Sennerby }} L_{\text {, Turri }} A$ Wennerberg A. Is Marginal Bone Loss around Oral Implants the Result of a Provoked Foreign Body Reaction? Clin Implant Dent Relat Res 2014; 16: 155-165.

42. Mouhyi J, Dohan Ehrenfest D M, Albrektsson T. The peri-implantitis: implant surfaces, microstructure, and physicochemical aspects. Clin Implant Dent Relat Res 2012; 14: 170-183.

43. Belibasakis GN. Microbiological and immuno-pathological aspects of peri-implant diseases. Arch Oral Biol 2014; 59: 66-72.

44. Zitzmann N U, Berglundh T, Marinello C P, Lindhe J. Experimental peri-implant mucositis in man. J Clin Periodontol 2001; 28: 517-523.

45. Lang N P, Berglundh T; Working Group 4 of VII European Workshop on Periodontology. Periimplant diseases: where are we now? Consensus of the Seventh European Workshop on Periodontology. J Clin Periodontol 2011; 11: 178-181.

46. Quirynen $M$, Vogels $R$, Peeters $W$, van Steenberghe $D$, Naert I, Haffajee A. Dynamics of initial subgingival colonization of 'pristine' peri-implant pockets. Clin Oral Implants Res 2006; 17: 25-37.

47. Teughels W, Van Assche N, Sliepen I, Quirynen M. Effect of material characteristics and/or surface topography on biofilm development. Clin Oral Implants Res 2006; 2: 68-81.

48. Berglundh T, Gotfredsen K, Zitzmann N U, Lang N P, Lindhe J. Spontaneous progression of ligature induced peri-implantitis at implants with different surface roughness: an experimental study in dogs. Clin Oral Implants Res 2007; 18: 655-661.

49. Lin H Y, Liu Y, Wismeijer D, Crielaard W, Deng D M. Effects of oral implant surface roughness on bacterial biofilm formation and treatment efficacy. Int $J$ Oral Maxillofac Implants 2013; 28: 1226-1231.

50. Sanz M, Chapple I L; Working Group 4 of the VIII European Workshop on Periodontology. Clinical research on peri-implant diseases: consensus report of Working Group 4. J Clin Periodontol 2012; 12: 202-206.

51. Hauser-Gerspach I, Vadaszan J, Deronjic I et al. Influence of gaseous ozone in peri-implantitis: bactericidal efficacy and cellular response. An in vitro study using titanium and zirconia. Clin Oral Investig 2012; 16: 1049-1059.

52. Salvi G E, Della Chiesa A, Kianpur P, Attström R, Schmidlin K, Zwahlen M, Lang N P. Clinical effects of interdental cleansing on supragingival biofilm formation and development of experimental gingivitis. Oral Health Prev Dent 2009; 7: 383-391.

53. Renvert S, Roos-Jansåker A M, Claffey N. Nonsurgical treatment of peri-implant mucositis and peri-implantitis: a literature review. J Clin Periodontol 2008; 35: 305-315.

54. Eke PI, Braswell L D, Fritz M E. Microbiota associated with experimental peri-implantitis and periodontitis in adult Macaca mulatta monkeys. J Periodontol 1998; 69: 190-194.

55. Berglundh T, Zitzmann N U, Donati M. Are periimplantitis lesions different from periodontitis lesions? J Clin Periodonto/ 2011; 11: 188-202.

56. Albouy J P, Abrahamsson I, Persson L G, Berglundh T. Spontaneous progression of peri-implantitis at different types of implants. An experimental study in dogs.l: clinical and radiographic observations. Clin Oral Implants Res 2008; 19: 997-1002.

57. Heitz-Mayfield L J, Lang N P. Comparative biology of chronic and aggressive periodontitis vs. periimplantitis. Periodontol 2000 2010; 53: 167-181.

58. John G, Becker J, Schwarz F. Modified implant surface with slower and less initial biofilm formation. Clin Implant Dent Relat Res 2013; DOI: 10.1111/ cid.12140.

59. Schmidlin P R, Müller P, Attin T, Wieland M, Hofer $D$, Guggenheim B. Polyspecies biofilm formation on implant surfaces with different surface characteristics. J App/ Oral Sci 2013; 21: 48-55.

60. Dahlin C, Nikfarid H, Alsén B, Kashani H. Apical peri-implantitis: possible predisposing factors, case reports, and surgical treatment suggestions. Clin Implant Dent Relat Res 2009; 11: 222-227.

61. Quirynen M, Vogels R, Alsaadi G, Naert I, Jacobs R, van Steenberghe $D$. Predisposing conditions for retrograde peri-implantitis, and treatment suggestions. Clin Oral Implants Res 2005; 16: 599-608.

62. Reiser G M, Nevins M. The implant periapical lesion: aetiology, prevention, and treatment. Compend Contin Educ Dent 1995: 16: 768, 770: 772 passim.

63. Canullo L, Fedele G R, lannello G, Jepsen S. Platform switching and marginal bone-level alterations: the results of a randomized-controlled trial. Clin Oral Implants Res 2010; 21: 115-121.

64. Rodríguez-Ciurana X, Vela-Nebot X, Segalà-Torres
M, Calvo-Guirado J L, Cambra J, Méndez-Blanco $V$, Tarnow D P. The effect of interimplant distance on the height of the interimplant bone crest when using platform-switched implants. Int J Periodontics Restorative Dent 2009; 29: 141-151.

65. Alani A, Corson M. Soft tissue manipulation for single implant restorations. Br Dent J 2011; 211: 411-416.

66. Tarnow D P, Cho S C, Wallace S S. The effect of interimplant distance on the height of inter-implant bone crest. J Periodontol 2000; 71: 546-549.

67. Hämmerle $C H$, Brägger U, Bürgin W, Lang N P. The effect of subcrestal placement of the polished surface of ITI implants on marginal soft and hard tissues. Clin Oral Implants Res 1996; 7: 111-119.

68. Linkevicius T, Apse P, Grybauskas S, Puisys A. The influence of soft tissue thickness on crestal bone changes around implants: a 1-year prospective controlled clinical trial. Int J Oral Maxillofac Implants 2009; 24: 712-719.

69. Fransson C, Lekholm U, Jemt T, Berglundh T. Prevalence of subjects with progressive bone loss at implants. Clin Oral Implants Res 2005; 16: 440-446.

70. Klinge B, Meyle J; Working Group 2. Peri-implant tissue destruction. The Third EAO Consensus Conference 2012. Clin Oral Implants Res 2012; 6: 108-110.

71. Atieh M A, Alsabeeha N H, Faggion CM Jr, Duncan W J. The frequency of peri-implant diseases: a systematic review and meta-analysis. J Periodontol 2013; 84: 1586-1598.

72. Tomasi C, Derks J. Clinical research of peri-implant diseases-quality ofreporting, case definitions and methods to study incidence, prevalence and risk factors of peri-implant diseases. J Clin Periodontol 2012: 12: 207-223

73. Needleman I, Chin S, O'Brien T, Petrie A, Donos N. Systematic review of outcome measurements and reference group(s) to evaluate and compare implant success and failure. J Clin Periodontol 2012; 12 : 122-132.

74. Cairo F, Sanz I, Matesanz P, Nieri M, Pagliaro U. Quality of reporting of randomized clinical trials in implant dentistry. A systematic review on critical aspects in design, outcome assessment and clinical relevance. J Clin Periodonto/ 2012; 12: 81-107.

75. Dumbrigue H B, Al-Bayat M I, Ng C C, Wakefield $C$ W. Assessment of bias in methodology for randomized controlled trials published on implant dentistry. J Prosthodont 2006; 15: 257-263.

76. Popelut A, Valet F, Fromentin O, Thomas A, Bouchard P. Relationship between Sponsorship and Failure Rate of Dental Implants: A Systematic Approach. PLOS ONE 2010; 5: e10274.

77. Renvert S, Lindahl C, Rutger Persson G. The incidence of peri-implantitis for two different implant systems over a period of thirteen years. J Clin Periodontol 2012; 39: 1191-1197.

78. Charalampakis G, Rabe P, Leonhardt A, Dahlén G. A follow-up study of peri-implantitis cases after treatment. J Clin Periodontol 2011; 38: 864-871.

79. Machtei E E, Mahler D, Oettinger-Barak O, Zuabi 0 , Horwitz J. Dental implants placed in previously failed sites: survival rate and factors affecting the outcome. Clin Oral Implants Res 2008; 19: 259-264. 